\title{
TINGKAT KEPERCAYAAN DAN MINAT BELI MASYARAKAT BANJARMASIN TERHADAP PRODUK HIJAU BERDASARKAN SEGMENTASI DEMOGRAFIS
}

\author{
Rizka Zulfikar $^{1}$, Prihatini Ade Mayvita ${ }^{2}$ \\ Email: ${ }^{1}$ rizkazulfikar@gmail.com, ${ }^{2}$ ademayvita@gmail.com \\ Fakultas Ekonomi Universitas Islam Kalimantan MAB Banjarmasin
}

\begin{abstract}
This study aims to assess the level of trust and intention in Banjarmasin's public purchasing towards green products based on demographic variables such as gender, age, income, occupation, education and its influence on the level of trust and intention in public purchasing. This study is a survey research using questionnaires as an instrument. Population and sample used in this study is the community of Banjarmasin and taken as many as 150 respondents using non-purposive sampling method. The analysis technique used is (1) descriptive analysis of qualitative - quantitative and comparative analysis of the average using SPSS software; (2) the influence and correlation test was analyzed with SEM using IBM AMOS Software Version 22. The study found that: (1) the level of confidence and interest in people's purchasing Banjarmasin city is good enough for assessment respondents in a category; (2) The demographic segments of potential that can be used as a target market of green products : female, age 31-40 years, selfemployed, earning between Rp 5 million - Rp 9,999 million and education level S-1 and S-3 (3) Segmentation demographic does not have a significant influence on the level of trust and intention in buying community towards green products because of the results of the SEM analysis for demoraphics CR value does not exceed 1.96 and the Sig. value is greater than 0.05 (4) demographic segmentation based on the type of work and level of education has a significant correlation only with trust variabels, but do not have a significant correlation with green purchase intention variabels.
\end{abstract}

Keywords : Trust, purchase intention, green products, demographic segmentation.

PENDAHULUAN

Meningkatnya jumlah konsumen yang menggunakan produk hijau (Green Costumer) dari waktu ke waktu merupakan potensi pasar tersendiri yang dapat digarap oleh para produsen untuk mengembangkan bisnis mereka.

Salah satu kegiatan untuk
memahami konsumen hijau dan
seringkali digunakan dalam kegiatan
pemasaran adalah melakukan segmentasi
atau mengelompokkan konsumen
berdasarkan pertimbangan tertentu.
Ada empat variabel utama yang umum


digunakan untuk melakukan segmentasi pasar, variabel demografis adalah variabel yang paling sering digunakan karena sifatnya yang mudah diukur dibanding variabel lainnya (Kotler dan Amstrong, 2012)

Faktor-faktor seperti gender, usia, tingkat penghasilan dan jenis pekerjaan berpengaruh terhadap minat beli produk hijau dalam rangka meningkatkan minat beli terhadap produk hijau (Schiffman dan Kanuk, 2008; Widyastuti dan Widagda, 2012; Hamzan dan Bayu, 2012).

Berbeda dengan teori dan pendapat-pendapat di atas, yakni berdasarkan temuan Jaolis (2011), Yahya (2011), Aryanti et al, (2014), Yasa (2015) dan Muzayanah (2015) yang menyatakan bahwa variabel demografis tidak memiliki pengaruh yang signifikan terhadap tingkat kepercayaan dan minat beli produk hijau.

Adanya perbedaan pendapat mengenai pengaruh demografis terhadap tingkat kepercayaan dan minat beli inilah yang melatar belakangi peneliti untuk melakukan penelitian dan menggali lebih jauh tentang seberapa besar tingkat kepercayaan dan minat beli masyarakat kota Banjarmasin terhadap produk hijau berdasarkan segmentasi demografis seperti gender, usia dan jenis pekerjaan, tingkat penghasilan, dan tingkat pendidikan dan pengaruh demografis terhadap kedua variabel tersebut.

\section{METODE PENELITIAN}

Penelitian ini dilaksanakan di Kota Banjarmasin pada bulan Mei hingga Agustus 2017 dan merupakan penelitian survey dengan menggunakan kuesioner sebagai instrumen yang menggunakan skala Likert dengan gradasi dari sangat positif sampai sangat negatif, dengan 5 alternatif jawaban.

Populasi adalah masyarakat kota Banjarmasin dan jumlah sampel yang digunakan dalam penelitian ini adalah sebanyak 150 sampel dan jumlah minimum sampel didapat dengan menggunakan rumus slovin sebagai berikut (Arikunto, 2010) : 
$\mathrm{n}=\frac{\mathrm{N} \cdot \mathrm{Z}^{2} 1-\propto / 2 \cdot \mathrm{p} \cdot(1-\mathrm{p})}{(N-1) d^{2}+\mathrm{Z}^{2} 1-\propto / 2 \cdot \mathrm{p} \cdot(1-\mathrm{p})}$

Dimana :

$\mathrm{n} \quad=$ Besar sampel minimum

$\mathrm{Z}=$ Nilai distribusi normal baku (tabel Z) pada $\propto=0.05$

$\mathrm{p}=$ Proporsi di populasi

$\mathrm{d}=$ Kesalahan (Absolut) yang dapat ditolerir

$\mathrm{N}=$ Besar populasi

Menurut BPS Banjarmasin, jumlah penduduk Banjarmasin hingga tahun 2016 mencapai 675.440 jiwa, dengan proporsi populasi $=10 \%$ dan tingkat kesalahan absolut yang dapat ditolerir adalah $5 \%$, maka besar sampel minimum yang digunakan dalam penelitian ini adalah sebagai berikut ;

$\mathrm{n}=\frac{675.440 \times(1,96)^{2} \times 0.1 \times 0.9}{(675439) x(0.05)^{2}+(1,96)^{2} \times 0.1 \times 0.9}=138$ sampel

Disain yang digunakan dalam penelitian adalah sebagai berikut :

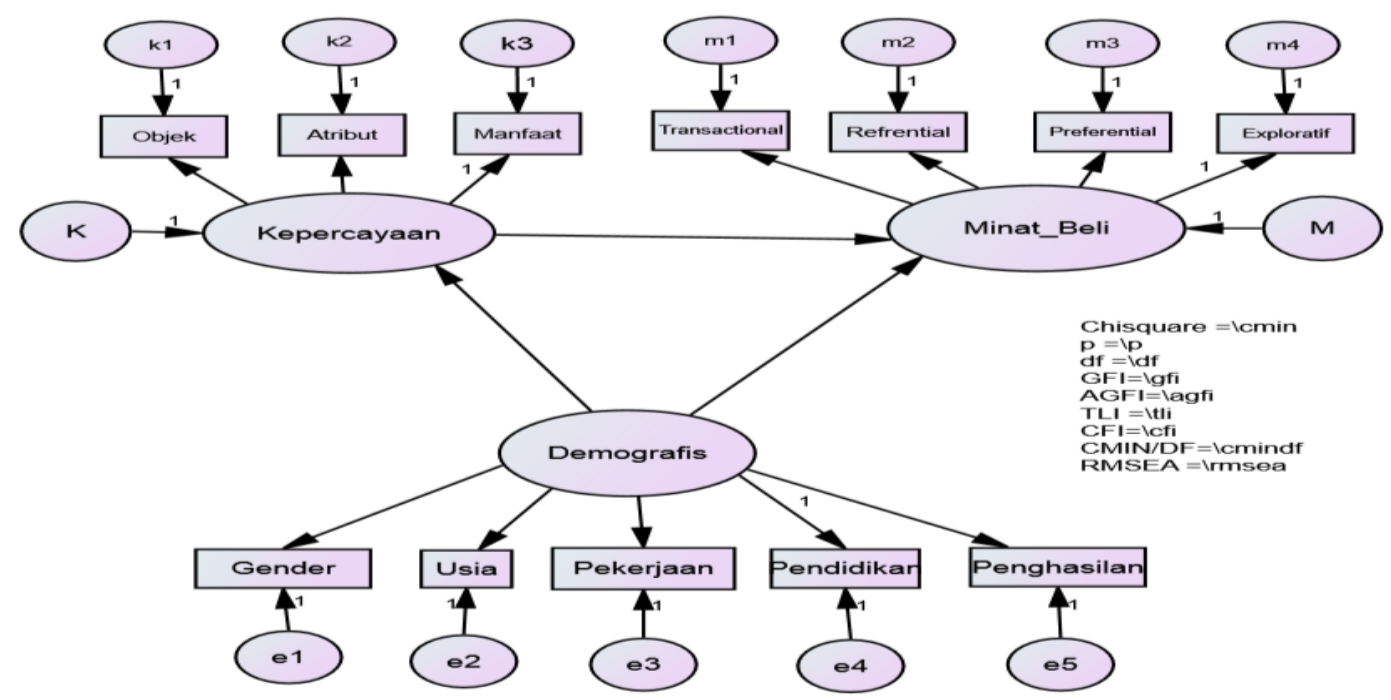

Gambar 1. Disain Penelitian

Hipotesis yang akan diuji dalam penelitian ini adalah sebagai berikut :

- Hipotesis I : Variabel demografis berpengaruh signifikan terhadap variabel kepercayaan dan minat beli produk hijau.

- Hipotesis II : Variabel demografis berkorelasi dengan variabel Tingkat Kepercayaan dan Minat Beli produk hijau. 


\section{HASIL DAN PEMBAHASAN}

\section{Analisis Deskripsi Kategori Variabel}

Penelitian ini terdiri dari 2 variabel yaitu Kepercayaan dan Minat Beli Produk Hijau. Deskripsi data yang disajikan meliputi Minimum, Maximum, Mean (M) dan standar deviasi (SD).

Tabel 1.

\section{Data Deskriptif Variabel}

\begin{tabular}{|l|r|r|r|r|r|}
\hline & N & \multicolumn{1}{c|}{ Min. } & \multicolumn{1}{c|}{ Max. } & Mean & \multicolumn{1}{c|}{ SD } \\
\hline Kepercayaan & 150 & 15.00 & 30.00 & 22.453 & 3.880 \\
Minat_Beli & 150 & 20.00 & 40.00 & 31.613 & 5.072 \\
Valid N & 150 & & & & \\
\hline
\end{tabular}

\section{Variabel Kepercayaan}

Hasil analisis deskriptif pada variabel Kepercayaan didapatkan nilai mínimum sebesar 15; nilai maksimum sebesar 30; mean sebesar 22,453; dan standar deviasi sebesar 3,880 .

Untuk hasil analisa deskriptif variabel Kepercayaan berdasarkan demografis dapat dilihat pada tabel di bawah ini.

Tabel 2.

\section{Kategorisasi Variabel Kepercayaan Berdasarkan Demografis}

\begin{tabular}{|l|c|c|c|c|c|c|}
\hline \multirow{2}{*}{ Faktor Demografis } & \multicolumn{2}{|c|}{ Tinggi } & \multicolumn{2}{c|}{ Sedang } & \multicolumn{2}{c|}{ Rendah } \\
\cline { 2 - 7 } & F & \% & F & \% & F & $\%$ \\
\hline Gender & & & & & & \\
$-\quad$ Laki-laki & 7 & 10,61 & 48 & 72,73 & 11 & 16,67 \\
$-\quad$ Perempuan & 11 & 13,10 & 56 & 66,67 & 17 & 20,24 \\
Usia & & & & & & \\
$-\quad$ Dibawah 20 Tahun & 1 & $14.29 \%$ & 5 & 71.43 & 1 & $14.29 \%$ \\
$-\quad 21-30$ Tahun & 5 & 17.24 & 17 & 58.62 & 7 & 24.14 \\
$-\quad$ 31 - 40 Tahun & 4 & 10.53 & 28 & 73.68 & 6 & 15.79
\end{tabular}




\begin{tabular}{|c|c|c|c|c|c|c|}
\hline 41 - 50 Tahun & 7 & $9.46 \%$ & 53 & 71.62 & 14 & $18.92 \%$ \\
\hline Di atas 50 Tahun & 1 & $50.00 \%$ & 1 & 50.00 & 0 & $0.00 \%$ \\
\hline \multicolumn{7}{|l|}{ Pekerjaan } \\
\hline Tidak Bekerja & 1 & $5.56 \%$ & 9 & 50.00 & 8 & $44.44 \%$ \\
\hline - $\quad$ Pelajar/Mahasiswa & 4 & $30.77 \%$ & 7 & 53.85 & 2 & $15.38 \%$ \\
\hline Pegawai Negeri & 0 & $0.00 \%$ & 15 & 75.00 & 5 & $25.00 \%$ \\
\hline Karyawan Swasta & 7 & $11.67 \%$ & 47 & 78.33 & 6 & $10.00 \%$ \\
\hline - Wiraswasta & 6 & $19.35 \%$ & 19 & 61.29 & 6 & $19.35 \%$ \\
\hline - $\quad$ Jasa Profesi & 0 & $0.00 \%$ & 7 & 87.50 & 1 & $12.50 \%$ \\
\hline \multicolumn{7}{|l|}{ Penghasilan } \\
\hline$-\quad<$ Rp 1 Juta & 0 & 0.00 & 12 & 100.00 & 0 & 0.00 \\
\hline Rp 1- Rp 2,49 Jt Juta & 0 & 0.00 & 4 & 33.33 & 8 & 66.67 \\
\hline Rp 2,5- Rp 4,9 Jt Juta & 8 & 19.05 & 29 & 69.05 & 5 & 11.90 \\
\hline - $\quad$ Rp 5- Rp 9,9 Jt & 10 & 20.41 & 34 & 69.39 & 5 & 10.20 \\
\hline$>$ Rp 10 Juta & 0 & 0.00 & 25 & 71.43 & 10 & 28.57 \\
\hline \multicolumn{7}{|l|}{ Pendidikan } \\
\hline - $\quad$ SD/SLTP/SLTA & 4 & 21.05 & 14 & 73.68 & 1 & $5.26 \%$ \\
\hline - Diploma (D1,D2, D3) & 4 & 50.00 & 4 & 50.00 & 0 & $0.00 \%$ \\
\hline$-\quad \mathrm{S}-1$ & 10 & 12.82 & 48 & 61.54 & 20 & $25.64 \%$ \\
\hline$-\quad S-2$ & 0 & 0.00 & 34 & 82.93 & 7 & $17.07 \%$ \\
\hline$-\quad S-3$ & 0 & 0.00 & 4 & 100.0 & 0 & 0.00 \\
\hline
\end{tabular}

Sumber : Data Primer (diolah), 2017.

Berdasarkan tabel di atas, maka hasil kategorisasi variabel kepercayaan berdasarkan segmentasi demografis adalah sebagai berikut :

a) Berdasarkan gender, nilai kepercayaan kategori tinggi cenderung lebih banyak diberikan oleh responden perempuan $(13.10 \%)$ daripada laki - laki $(10.61 \%)$.

b) Berdasarkan usia, nilai kepercayaan kategori tinggi cenderung lebih banyak diberikan oleh responden dalam kelompok usia $21-30$ Tahun (17.24\%) dibandingkan kelompok usia lainya.

c) Berdasarkan jenis pekerjaan, nilai kepercayaan kategori tinggi cenderung lebih banyak diberikan oleh responden dengan pekerjaan pelajar/mahasiswa $\quad(30.7 \%)$, dibandingkan kelompok pekerjaan lainnya.

d) Berdasarkan tingkat penghasilan, nilai kepercayaan kategori tinggi cenderung lebih banyak diberikan oleh responden dengan tingkat penghasilan Rp 5 Juta - Rp 9,999 Juta (20.41 \%) dibandingkan 
kelompok penghasilan lainya.

e) Berdasarkan tingkat pendidikan, nilai kepercayaan kategori tinggi cenderung lebih banyak diberikan oleh responden dengan tingkat pendidikan Diploma (50.00 \%), dibandingkan kelompok responden dengan tingkat pendidikan lainnya.
Namun secara keseluruhan dapat dikatakan bahwa berdasarkan demografis, tingkat kepercayaan masyarakat Banjarmasin terhadap produk hijau sudah cukup baik dan masih dapat ditingkatkan untuk seluruh kelompok faktor demografis.

\section{Variabel Minat Beli}

Hasil analisa deskriptif variabel minat beli berdasarkan demografis dapat dilihat pada tabel di bawah ini.

Tabel. 3

Kategorisasi Variabel Minat Beli Berdasarkan Demografis

\begin{tabular}{|l|c|c|c|c|c|c|}
\hline \multirow{2}{*}{ Faktor Demografis } & \multicolumn{2}{|c|}{ Tinggi } & \multicolumn{2}{c|}{ Sedang } & \multicolumn{2}{c|}{ Rendah } \\
\cline { 2 - 7 } & F & \% & F & \% & F & $\%$ \\
\hline Gender & & & & & & \\
- Laki-laki & 11 & 16.67 & 47 & 71.21 & 8 & 12.12 \\
- Perempuan & 24 & 28.57 & 50 & 59.52 & 10 & 11.90 \\
Usia & & & & & & \\
- Dibawah 20 Tahun & 4 & 57.14 & 1 & 14.29 & 2 & $28.57 \%$ \\
- 21 - 30 Tahun & 7 & 24.14 & 17 & 58.62 & 5 & $17.24 \%$ \\
- 31 - 40 Tahun & 5 & 13.51 & 26 & 70.27 & 6 & $16.22 \%$ \\
- 41 - 50 Tahun & 19 & 25.33 & 52 & 69.33 & 4 & 5.33 \\
- Di atas 50 Tahun & 0 & $0.00 \%$ & 1 & 50.00 & 1 & $50.00 \%$ \\
Pekerjaan & & & & & & \\
- Tidak Bekerja & 4 & 23.53 & 13 & 76.47 & 0 & 0.00 \\
- Pelajar/Mhsiswa & 3 & 42.86 & 4 & 57.14 & 0 & 0.00 \\
- Pegawai Negeri & 6 & 30.00 & 11 & 55.00 & 3 & $15.00 \%$ \\
- Karyawan Swasta & 10 & 15.63 & 44 & 68.75 & 10 & $15.63 \%$ \\
- Wiraswasta & 12 & 35.29 & 18 & 52.94 & 4 & $11.76 \%$ \\
- Jasa Profesi & 0 & 0.00 & 7 & 87.50 & 1 & $12.50 \%$ \\
Penghasilan & & & & & & \\
- < Rp 1 Juta & 7 & 58.33 & 5 & 41.67 & 0 & 0.00 \\
- Rp 1- Rp 2,49 Jt & 0 & 0.00 & 8 & 66.67 & 4 & $33.33 \%$ \\
- Rp 2,5- Rp 4,9 Jt & 10 & 23.81 & 22 & 52.38 & 10 & $23.81 \%$ \\
- Rp 5- Rp 9,9 Jt & 11 & 22.45 & 37 & 75.51 & 1 & 2.04 \\
- >Rp 10 Juta & 7 & 20.00 & 25 & 71.43 & 3 & 8.57 \\
Pendidikan & & & & & & \\
\hline
\end{tabular}




\begin{tabular}{|l|c|c|c|c|c|c|}
\hline$-\mathrm{SD} / \mathrm{SLTP} / \mathrm{SLTA}$ & 7 & 35.00 & 11 & 55.00 & 2 & $10.00 \%$ \\
$-\mathrm{D} 1, \mathrm{D} 2, \mathrm{D} 3$ & 4 & 57.14 & 0 & $0.00 \%$ & 3 & $42.86 \%$ \\
$-\mathrm{S}-1$ & 14 & 17.95 & 58 & 74.36 & 6 & 7.69 \\
$-\mathrm{S}-2$ & 6 & 14.63 & 28 & 68.29 & 7 & $17.07 \%$ \\
$-\mathrm{S}-3$ & 4 & $100.00 \%$ & 0 & $0.00 \%$ & 0 & 0.00 \\
\hline
\end{tabular}

Sumber : Data Primer (diolah), 2017.

Berdasarkan tabel di atas, maka hasil kategorisasi variabel minat beli berdasarkan segmentasi demografis adalah sebagai berikut :

a) Berdasarkan gender, nilai minat beli kategori tinggi cenderung lebih banyak diberikan oleh responden perempuan $(28.57 \%)$ daripada laki - laki (71.21\%).

b) Berdasarkan usia, nilai minat beli kategori tinggi cenderung lebih banyak diberikan oleh responden dalam kelompok usia di bawah 20 Tahun (57.14\%) dibandingkan kelompok usia lainnya.

c) Berdasarkan jenis pekerjaan, nilai minat beli kategori tinggi cenderung lebih banyak diberikan oleh responden dengan pekerjaan pelajar/mahasiswa $(42.86 \%)$, dibandingkan kelompok jenis pekerjaan lainnya.

d) Berdasarkan tingkat penghasilan, nilai minat beli kategori tinggi cenderung lebih banyak diberikan oleh responden dengan tingkat penghasilan di bawah Rp 1 Juta (58.33 \%), dibandingkan kelompok penghasilan lainya.

e) Berdasarkan tingkat pendidikan, nilai minat beli kategori tinggi cenderung lebih banyak diberikan oleh responden dengan tingkat pendiikan S-3 (100.00 \%), dibandingkan kelompok responden dengan tingkat pendidikan lainnya.

Namun secara keseluruhan dapat dikatakan bahwa berdasarkan demografis, minat beli masyarakat Banjarmasin terhadap produk hijau mayoritas dalam kategori sedang dan sudah cukup baik sehingga masih dapat ditingkatkan untuk seluruh kelompok faktor demografis.

\section{Uji Perbandingan Rata-rata}

Analisa menggunakan data ratarata penilaian responden terhadap variabel dependent dan dibandingkan dengan masing-masing kelompok segementasi. Analisa dilakukan untuk mengetahui kelompok segmentasi 
Volume 3 Nomor 2, Oktober 2017

potensial, maka hasil penilaian seluruh kelompok segmentasi masyarakat dikelompokkan sesuai demografis terhadap variabel kelompok segmentasi dan dilakukan kepercayaan dan minat beli masyarakat analisis perbandingan rata-rata jumlah skor untuk setiap kelompok. terhadap produk hijau disajikan pada tabel berikut ini :

Hasil perbandingan rata-rata

Tabel. 4

Rata-Rata Tanggapan Responden Terhadap Kepercayaan dan Minat Beli

\begin{tabular}{|c|c|c|}
\hline \multirow[t]{2}{*}{ Faktor Demografis } & \multicolumn{2}{|c|}{ Rata-rata Tanggapan } \\
\hline & Kepercayaan & Minat Beli \\
\hline $\begin{array}{l}\text { Gender } \\
\text { - Laki-laki } \\
\text { - Perempuan } \\
\text { Usia } \\
\text { - Dibawah } 20 \text { Tahun } \\
\text { - } 21 \text { - 30 Tahun } \\
\text { - } 31 \text { - } 40 \text { Tahun } \\
\text { - } 41 \text { - 50 Tahun } \\
\text { - Di atas 50 Tahun } \\
\text { Pekerjaan } \\
\text { - } \quad \text { Tidak Bekerja } \\
\text { - Pelajar/Mahasiswa } \\
\text { - } \quad \text { Pegawai Negeri } \\
\text { - } \quad \text { Karyawan Swasta } \\
\text { - Wiraswasta } \\
\text { - Jasa Profesi } \\
\text { Penghasilan } \\
\text { - } \quad \text { Rp 1 Juta } \\
\text { - Rp 1- Rp 2,49 Jt } \\
\text { - } \quad \text { Rp 2,5- Rp 4,9 Jt } \\
\text { - } \quad \text { Rp 5- Rp 9,9 Jt } \\
\text { - } \quad \text { Rp 10 Juta } \\
\text { Pendidikan } \\
\text { - SD/SLTP/SLTA } \\
\text { - D1,D2, D3 } \\
\text { - S-1 } \\
\text { - S-2 } \\
\text { - S-3 }\end{array}$ & $\begin{array}{c}22.38 \\
22.95 \\
\left.24.29^{*}\right) \\
22.20 \\
24.00 \\
\\
21.24 \\
\left.24.29^{*}\right) \\
21.65 \\
22.88 \\
23.00 \\
19.75 \\
\\
23.16 \\
19.83 \\
23.21 \\
\left.23.92^{*}\right) \\
20.94 \\
\\
24.21 \\
22.23 \\
\left.26.50^{*}\right) \\
21.17 \\
26.00\end{array}$ & $\begin{array}{c}30.67 \\
\left.32.36^{*}\right) \\
\\
29.83 \\
29.53 \\
\left.34.29^{*}\right) \\
32.54 \\
32.00 \\
\\
32.76 \\
32.29 \\
31.25 \\
30.64 \\
\left.33.82^{*}\right) \\
27.88\end{array}$ \\
\hline
\end{tabular}

Sumber: Data Primer diolah, 2017 
Berdasarkan tabel di atas, maka hasil perbandingan rata-rata masingmasing segmen demografis adalah sebagai berikut :

a) Berdasarkan gender, perempuan cenderung memiliki tingkat kepercayaan dan minat beli yang lebih baik daripada laki-laki. Hal ini sejalan dengan temuan Mostafa (2006), Lee (2009) dan Yasa (2015) yang menyatakan bahwa tingkat kepercayaan dan minat beli terhadap produk yang berkaitan erat dengan isu lingkungan cenderung didominasi oleh konsumen perempuan.

b) Berdasarkan usia, kelompok usia antara 31 - 40 tahun cenderung memiliki tingkat kepercayaan dan minat beli yang lebih baik daripada kelompok usia responden lainnya. Meskipun berbeda, namun hasil penelitian ini hampir mendekati hasil temuan Dumanovsky et al (2010) yang menyatakan bahwa kesadaran konsumen terkait dengan produk makanan sehat cenderung dimiliki oleh kelompok umur 20 tahun hingga 50 tahun.

c) Berdasarkan pekerjaan, responden yang memiliki pekerjaan sebagai pelajar atau mahasiswa cenderung memiliki tingkat kepercayaan yang lebih baik daripada kelompok kategori pekerjaan lainnya. Sedangkan responden dengan pekerjaan sebagai wiraswasta cenderung memiliki minat beli yang lebih baik daripada kelompok lainnya. Hal ini menunjukkan bahwa perbedaan pekerjaan konsumen juga menimbulkan perilaku konsumsi barang-barang yang berbeda pula dengan konsumen dengan jenis pekerjaan lainnya (Kasali, 2007).

d) Berdasarkan penghasilan, kelompok responden dengan tingkat penghasilan Rp 5 Juta - Rp 9,999 juta cenderung memiliki tingkat kepercayaan dan minat beli yang lebih baik daripada kelompok lainnya. Hal ini juga menunjukkan bahwa semakin tinggi penghasilan konsumen maka tingkat kepercayaan dan minat beli cenderung untuk meningkat meskipun dari hasil penelitian kelompok dengan penghasilan 10 juta ke atas hanya menempati urutan kedua dalam hal minat beli terhadap produk hijau setelah kelompok 
Volume 3 Nomor 2, Oktober 2017

dengan penghasilan Rp 5 Juta - Rp 9,999 Juta.

e) Berdasarkan pendidikan, responden dengan pendidikan Sarjana (S-1) cenderung memiliki tingkat kepercayaan yang lebih baik daripada kelompok lainnya sedangkan responden dengan pendidikan Doktor (S-3) cenderung memiliki minat beli yang paling tinggi dibanding kelompok lainnya. Hal ini karena dengan tingkat pendidikan yang baik, maka pemahaman dan pengetahuan terhadap sesuatu akan lebih baik, dan menjadi dasar pertimbangan dalam melakukan pembelian produk hijau (Tsakiridou, 2012).

\section{Analisis SEM}

\section{Model SEM Penelitian}

Hasil analisis terhadap data yang digunakan dalam penelitian ini menghasilkan model SEM dapat dilihat pada gambar 2 berikut ini.

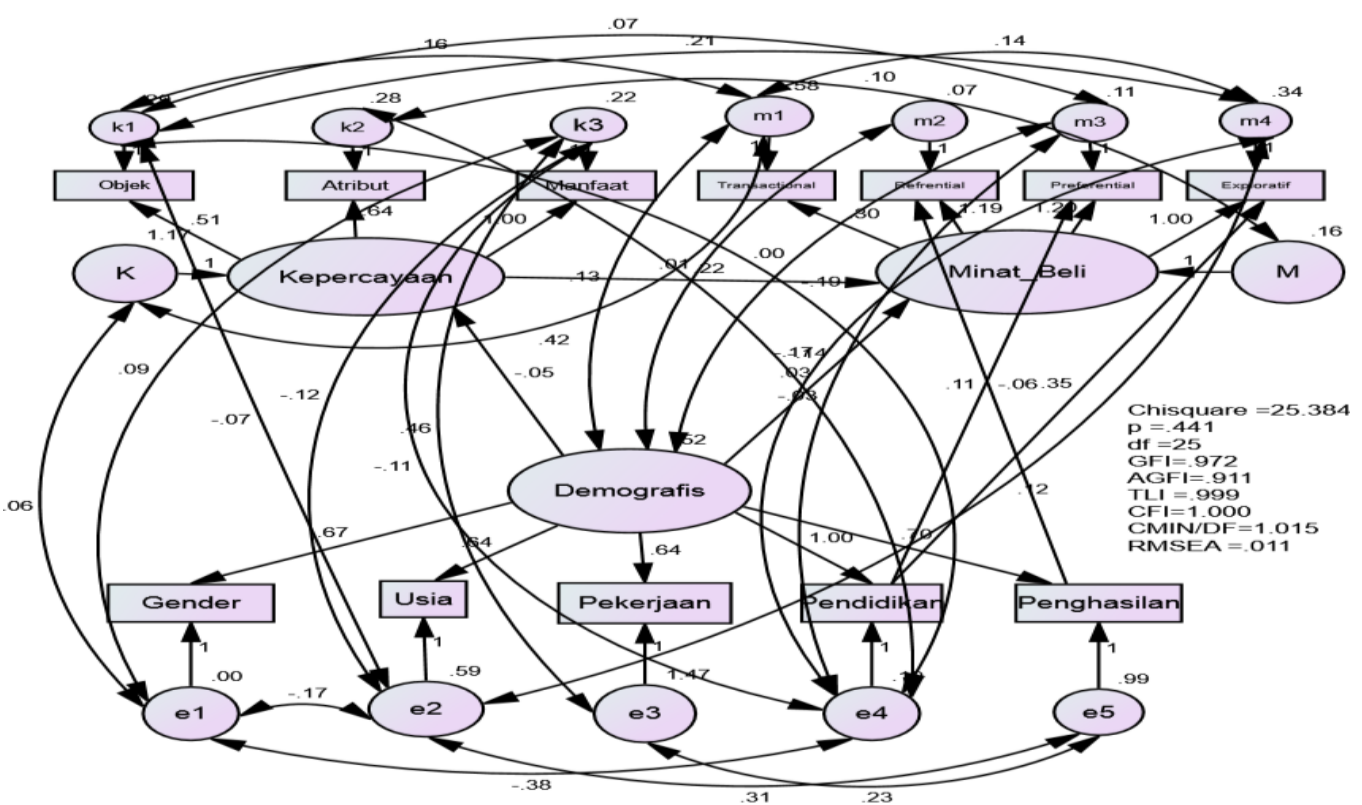

Gambar 2. Model SEM Hasil Penelitian

Berdasarkan model penelitian yanng didapatkan maka perbandingan hasil penelitian berdasarkan kriteria Goodness Of Fit (GOF) yang disyaratkan untuk analisis kesesuaian model antara lain adalah sebagai berikut : 
Tabel. 5

Hasil Uji Model Penelitian

\begin{tabular}{|l|ccc|}
\hline $\begin{array}{c}\text { Goodness of Fit } \\
\text { (GOF) Index }\end{array}$ & $\begin{array}{c}\text { Cut Off } \\
\text { Value }\end{array}$ & $\begin{array}{c}\text { Hasil } \\
\text { Penelitian }\end{array}$ & $\begin{array}{c}\text { Evaluasi } \\
\text { Model }\end{array}$ \\
\hline Chi Square & Kecil & 25,384 & Kecil \\
Probability & $\geq 0.05$ & 0.441 & Baik \\
GFI & $\geq 0.9$ & 0.972 & Baik \\
AGFI & $\geq 0.9$ & 0.911 & Baik \\
TLI & $\geq 0.95$ & 0.999 & Baik \\
CFI & $\geq 0.95$ & 1.000 & Baik \\
CMIN/DF & $\leq 2,00$ & 1.015 & Baik \\
RMSEA & $\leq 0.080$ & 0.011 & Baik \\
\hline
\end{tabular}

Berdasarkan hasil ini, maka dapat dikatakan bahwa model penelitian telah memiliki tingkat Goodness Of Fit (GOF) yang baik.

\section{Evaluasi Kesesuaian Model}

Berdasarkan model penelitian yang telah dimodifikasi didapatkan bahwa kriteria Goodness Of Fit (GOF) yang disyaratkan untuk analisis kesesuaian model antara lain adalah sebagai berikut :

Tabel. 6

Hasil Uji Model Penelitian Sebelum dan Sesudah Modifikasi

\begin{tabular}{|l|c|c|c|l|}
\hline $\begin{array}{c}\text { Kriteria } \\
\text { Goodness of } \\
\text { Fit (GOF) }\end{array}$ & $\begin{array}{c}\text { Cut } \\
\text { Off }\end{array}$ & $\begin{array}{c}\text { Model } \\
\text { Sebelum } \\
\text { Modifikasi }\end{array}$ & $\begin{array}{c}\text { Model } \\
\text { Sesudah } \\
\text { Modifikasi }\end{array}$ & Kesimpulan \\
\hline Chi Square & Kecil & 25,384 & 7.044 & Semakin Baik \\
Probability & $\geq 0.05$ & 0.441 & 0.633 & Semakin Baik \\
GFI & $\geq 0.9$ & 0.972 & 0.989 & Semakin Baik \\
AGFI & $\geq 0.9$ & 0.911 & 0.945 & Semakin Baik \\
TLI & $\geq 0.95$ & 0.999 & 1.013 & Semakin Baik \\
CFI & $\geq 0.95$ & 1.000 & 1.000 & Baik \\
\hline CMIN/DF & $\leq 2,00$ & 1.015 & 0.783 & Semakin Baik \\
RMSEA & $\leq 0.08$ & 0.011 & 0.000 & Semakin Baik \\
\hline
\end{tabular}

Dari hasil modifikasi model penelitian, seluruh kriteria yang dipersyaratkan goodness of fit index semakin membaik dimana pada perhitungan nilai Chi Square pada model penelitian sebelumnya diperoleh nilai sebesar 25.384 dan setelah dimodifikasi semakin turun menjadi 7.044. Nilai probablitas sebelumnya sebesar 0.441 menjadi naik 0.633 Nilai Goodness Of Fit Index (GFI) sebelumnya sebesar 0.972 menjadi 
naik sebesar 0.989 dan nilai Adjusted Godness Of Fit Index (GFI) sebesar 0.911 menjadi 0.945 setelah model dimodifikasi. Untuk nilai Tucker Lewis Index (TLI) yang sebelumnya diperoleh sebesar 0.999 menjadi lebih baik setelah model dimodifikasi dengan nilai TLI 1.013. Nilai Comparative Fit Index (CFI) baik pada model sebelum dan sesudah modifikasi tetap di angka 1.000. Model penelitian yang telah dimodifikasi juga memberikan nilai CMIN/DF dan RMSEA menjadi lebih baik bahkan nilai RMSE setelah modifikasi mampu mencapai nilai 0.000 Berdasarkan hasil ini, maka dapat dikatakan bahwa modifikasi model penelitian telah meningkatkan Goodness Of Fit (GOF) model penelitian menjadi lebih baik.

\section{Pengujian Hipotesis I}

Pengujian hipotesis I dilakukan dengan mengamati nilai CR dan Sig variabel yang diteliti berdasarkan maximum likelihood estimates dengan melihat tabel regreesion weights, dimana dikatakan memberikan pengaruh yang signifikan apabila nilai $\mathrm{CR}$ variabel $>1.96$ dan probabilitas $<0.05$. Hasil uji pengaruh antar variabel yang diuji berdasarkan model yang telah dimodifikasi ditampilkan pada tabel berikut :

Tabel 7

Hasil Uji Pengaruh

(Regression Weights-Maximum Likelihood Estimates)

\begin{tabular}{|c|c|c|c|c|c|c|}
\hline & & & Estimate & C.R. & $\overline{\mathbf{P}}$ & Kesimpulan \\
\hline Kepe & & $\overline{\text { Demografis }}$ & -0.053 & -0.292 & 0.77 & Terima $\mathrm{H}_{0}$ \\
\hline Minat_Beli & $\leftarrow$ & Demografis & 0.031 & 0.48 & 0.631 & Terima $\mathrm{H}_{0}$ \\
\hline Minat_Beli & $\leftarrow$ & Kepercayaan & 0.200 & 4.115 & $* * *$ & Tolak $\mathrm{H}_{0}$ \\
\hline
\end{tabular}

***) $\mathrm{P}=$ Dibawah 0.05 dan nilai $\mathrm{CR}>1.96$

Berdasarkan tabel di atas, maka hasil uji hipotesis adalah sebagai berikut.

a. Variabel demografis tidak berpengaruh signifikan terhadap tingkat kepercayaan masyarakat dimana nilai CR $(-0.292)<1.96$ dan probabilitas $>0.05$ sehingga $\mathrm{H}_{0}$ diterima.

b. Variabel demografis tidak berpengaruh signifikan terhadap minat beli masyarakat dimana nilai CR $(0.480)<1.96$ dan probabilitas $>0.05$ sehingga $\mathrm{H}_{0}$ diterima.

c. Variabel kepercayaan berpengaruh 
signifikan terhadap minat beli masyarakat dimana nilai CR (4.115) $>1.96$ dan probabilitas lebih kecil dari 0.05 .

Dalam penelitian ini karena adanya faktor-faktor yang tidak reliabel sehingga hanya faktor seperti gender, jenis pekerjaan dan tingkat pendidikan saja yang mewakili variabel demografis sedangkan faktor seperti usia dan tingkat penghasilan harus dikeluarkan dari model penelitian

Hasil penelitian memang tidak mendukung dengan temuan Schiffman dan Kanuk (2008), Widyastuti dan Widagda (2012), Hamzan dan Bayu (2012) yang menyatakan bahwa faktor demografis berpengaruh terhadap tingkat kepercayaan dan minat beli produk hijau. Namun sejalan dengan temuan dari Berkowitz dan Lutterman, (1968); Anderson dan Cunningham, (1972); dalam Jaolis (2011), Yahya (2011), Syahbandi (2012), Aryanti et al (2014), dan Muzayanah dkk (2015) yang menyatakan bahwa faktor demografis tidak memiliki pengaruh terhadap tingkat kepercayaan dan miinat beli masyarakat terhadap produk hijau.

\section{Pengujian Hipotesis II}

Pengujian hipotesis II dilakukan dengan mengamati nilai CR dan Sig variabel yang diteliti berdasarkan nilai estimasi korelasi dan kavarint, dimana dikatakan memiliki korelasi yang signifikan apabila nilai $\mathrm{CR}$ variabel > 1.96 dan probabilitas $<0.05$. Semakin mendekati nilai 1 maka tingkat korelasi semakin kuat, sedangkan nilai positif dan negatif pada estimasi korelasi hanya menunjukkan arah dari hubungan korelasi antar variabel yang diamati. Di dalam SEM, variabelvariabel yang ditampilkan hanyalah variabel yang terindikasi berkorelasi di dalam model penelitian dan hasil uji korelasi antar variabel yang terindikasi memiliki korelasi di dalam model ditabulasikan pada tabel berikut : 
Tabel 8.

Hasil Uji Korelasi

\begin{tabular}{|c|c|c|c|c|c|c|c|c|}
\hline \multicolumn{3}{|c|}{ Hubungan } & $\begin{array}{l}\text { Estimasi } \\
\text { Korelasi }\end{array}$ & $\begin{array}{c}\text { Estimasi } \\
\text { Kovarian }\end{array}$ & S.E. & C.R. & $\mathbf{P}$ & $\begin{array}{c}\text { Kesim } \\
\text { pulan }\end{array}$ \\
\hline Objek & $\begin{array}{l}<-- \\
> \\
<--\end{array}$ & Eksploratif & 0.645 & 0.193 & $\begin{array}{r}0.03 \\
5\end{array}$ & $\begin{array}{r}5.57 \\
-\end{array}$ & $* * *$ & $\begin{array}{c}\text { Tolak } \\
\left.\mathrm{H}_{0} *\right) \\
\text { Tolak }\end{array}$ \\
\hline Objek & $\begin{array}{l}> \\
<--\end{array}$ & Pendidikan & -1.088 & -0.281 & $\begin{array}{r}0.082 \\
0.02\end{array}$ & 3.426 & $* * *$ & $\begin{array}{l}\left.\mathrm{H}_{0} *\right) \\
\text { Tolak }\end{array}$ \\
\hline Atribut & $\begin{array}{l}> \\
<--\end{array}$ & Minat Beli & 0.474 & 0.104 & 4 & 4.255 & $* * *$ & $\begin{array}{l}\left.\mathrm{H}_{0}^{*}\right) \\
\text { Terima }\end{array}$ \\
\hline Objek & $\begin{array}{l}> \\
<--\end{array}$ & Preferential & 0.393 & 0.071 & 0.022 & 3.223 & 0.001 & $\begin{array}{c}\mathrm{H}_{0} \\
\text { Terima }\end{array}$ \\
\hline Atribut & $\begin{array}{l}> \\
<--\end{array}$ & Pendidikan & -0.793 & -0.206 & 0.087 & $\begin{array}{r}2.377 \\
5.05\end{array}$ & 0.017 & $\begin{array}{c}\mathrm{H}_{0} \\
\text { Tolak }\end{array}$ \\
\hline Pekerjaan & $\begin{array}{l}> \\
<--\end{array}$ & Manfaat & 0.881 & 0.486 & 0.096 & 1 & $* * *$ & $\begin{array}{c}\left.\mathrm{H}_{0} *\right) \\
\text { Terima }\end{array}$ \\
\hline Refrential & $\begin{array}{l}> \\
<--\end{array}$ & Demografis & -0.009 & -0.002 & 0.039 & 0.045 & 0.964 & $\begin{array}{c}\mathrm{H}_{0} \\
\text { Terima }\end{array}$ \\
\hline Exploratif & $\begin{array}{l}> \\
<--\end{array}$ & Demografis & -0.007 & -0.002 & 0.043 & -0.04 & 0.968 & $\begin{array}{c}\mathrm{H}_{0} \\
\text { Terima }\end{array}$ \\
\hline Manfaat & $\begin{array}{l}> \\
<--\end{array}$ & Pendidikan & -1.009 & -0.223 & $\begin{array}{r}0.158 \\
0.06\end{array}$ & 1.409 & 0.159 & $\begin{array}{c}\mathrm{H}_{0} \\
\text { Terima }\end{array}$ \\
\hline Prefrential & $\begin{array}{l}> \\
<--\end{array}$ & Pendidikan & -0.183 & -0.03 & 8 & -0.44 & 0.660 & $\begin{array}{c}\mathrm{H}_{0} \\
\text { Terima }\end{array}$ \\
\hline Exploratif & $>$ & Pendidikan & -0.211 & -0.057 & 0.084 & 0.676 & 0.499 & $\mathrm{H}_{0}$ \\
\hline
\end{tabular}

Berdasarkan hasil di atas, maka didapatkan 4 korelasi antarvariabel yang signifikan yaitu :

a) Indikator kepercayaan objek secara signifikan berkorelasi positif - kuat (0.645) dengan indikator exploratif secara signifikan karena nilai CR > 1.96 dan probabilitas $<0.05$.

b) Indikator kepercayaan objek secara signifikan berkorelasi negatif - kuat (-1.088) dengan indikator pendidikan karena nilai
CR > 1.96 dan probabilitas < 0.05 .

c) Indikator kepercayaan atribut secara signifikan berkorelasi positif - lemah (0.474) dengan variabel minat beli karena nilai CR > 1.96 dan probabilitas < 0.05 .

d) Indikator pekerjaan secara signifikan berkorelasi positif kuat (0.881) dengan indikator kepercayaan manfaat karena nilai CR > 1.96 dan probabilitas < 
0.05 .

e) Hubungan antar indikator lainnya didapatkan tidak berkorelasi secara signifikan karena nilai CR $<1.996$ dan probabilitas $>0.05$.

Hasil penelitian ini menemukan bahwa hanya indikator pendidikan dan pekerjaan yang memiliki korelasi dengan indikator kepercayaan meskipun tidak berkorelasi dengan indikator minat beli. Hal ini mendukung pernyataan Berkowitz dan Lutterman (1968); Anderson dan Cunningham (1972) dalam Jaolis (2011) dan selanjutnya pernyaataan Sethuraman dan Cole (1999) dalam Junaedi (2008) serta Muzayanah dkk (2015) yang menyatakan bahwa faktor-faktor demografis tidak memiliki korelasi terhadap variabel minat beli masyarakat terhadap produk hijau.

\section{KESIMPULAN DAN SARAN}

\section{Kesimpulan}

Berdasarkan hasil analisis data dan temuan penelitian, maka beberapa kesimpulan yang dapat diambil adalah sebagai berikut :

1) Tingkat kepercayaan masyarakat kota Banjarmasin terhadap produk hijau mayoritas sudah cukup baik secara demografis karena sebagian besar responden $(69,33 \%)$ memberikan penilaian pada tingkat kepercayaan terhadap produk hijau dalam kategori sedang.

2) Minat beli masyarakat kota Banjarmasin terhadap produk hijau mayoritas sudah cukup baik baik secara demografis dan psikografis karena sebagian besar responden yakni sebesar $64.67 \%$ memberikan penilaian pada variabel minat beli terhadap produk hijau dalam kategori sedang.

3) Segmentasi demografis potensial berdasarkan rata-rata tingkat kepercayaaan dan minat beli terhadap produk hijau tertinggi antara lain adalah :

- Kelompok berdasarkan Gender:

Perempuan

- Kelompok berdasarkan Usia: 31 - 40 Tahun

- Kelompok berdasarkan pekerjaan: Pelajar, Mahasiswa dan Wiraswasta

- Kelompok berdasaran penghasilan: Rp 5 Juta - Rp 9,999 Juta

- Kelompok berdasarkan 
pendidikan: S-1 dan S-3

4) Variabel demografis sepeti gender, jenis pekerjaan dan tingkat pendidikan tidak mempengaruhi variabel kepercayaan dan minat beli masyarakat terhadap produk hijau secara signifikan karena seluruh nilai signifikansi seluruh faktor yang diamati bernilai lebih besar dari 0.05. Sedangkan untuk indikator usia dan tingkat penghasilan dapat dikatakan tidak termasuk yang dianalisa karena indikator ini tidak valid dan tidak reliabel sehingga harus dikeluarkan dari model penelitian.

5) Segmentasi demografis berdasarkan jenis pekerjaan dan tingkat pendidikan cenderung lebih berkaitan dengan tingkat kepercayaan masyarakat dibandingkan dengan minat belinya. Indikator jenis pekerjaan dan tingkat pendidikan memiliki korelasi yang signifikan hanya dengan indikator kepercayaan, namun tidak memiliki korelasi yang signifikan dengan indikator-indikator minat beli.

\section{Saran}

Beberapa saran yang dapat disampaikan untuk penelitian di masa yang akan datang antara lain adalah :

1) Populasi penelitian dapat lebih diperluas dan tidak hanya untuk masyarakat satu kota saja agar didapatkan gambaran yang lebih jelas tentang pengaruh dan korelasi segmentasi demografis dengan tingkat kepercayaan dan minat beli masyarakat terhadap produk hijau.

2) Variabel penelitian dapat dikembangkan lebih lanjut dengan meneliti pengaruh segmentasi psikografis dan segmentasi perilaku agar“didapatkan gambaran yang komprehensif tentang variabelvariabel segmentasi yang mempengaruhi tingkat kepercayaan dan minat beli masyarakat terhadap produk hijau.

3) Pengembangan produk hijau perlu mempertimbangkan indikatorindikator yang lebih dominan dipertimbangkan masyarakat dalam menetapkan kepercayaan dan minat beli mereka terhadap produk hijau. 


\section{DAFTAR PUSTAKA}

Arikunto, S. 2010. Prosedur Penelitian: Suatu Pendekatan Praktik. Edisi 7. PT. Rineka Cipta. Jakarta.

Aryanti, T. Utami, R.D. dan Gunarsih. 2014. Pengaruh Pengetahuan, Kepedulian, dan Sikap pada Lingkungan terhadap Minat Pembelian Produk Hijau. Media Trend. 9(2) : 151-161.

Biro Pusat Statistik. 2016. Banjarmasin Dalam Angka Tahun 2016. BPS Kota Banjarmasin.

D'Souza, C. Taghian, M. dan Khosla, R. 2007. Examination Of Environmental Beliefs And Its Impact On The Influence Of Price, Quality And Demographic Characteristics With Respect To Green Purchase Intention. Journal Of Targeting, Measurement And Analysis For Marketing, 15(2) : 69-78.

Dumanovsky, T. Huang, C.Y. Bassett, M.T. dan Silver. L. D. 2010. Consumer Awareness of Fast-Food Calorie Information in New York City After Implementation of a Menu Labeling Regulation, American Journal of Public Health, December. 100 (12) : 2520-2525.

Ferdinand, A. 2002. Structural Equation Modelling dalam Penelitian Manajemen. FE UNDIP. Semarang.

Ghozali, I dan Fuad, (2011). Structural Equation Modeling : Teori, Konsep, dan Aplikasi dengan
Program AMOS 21. Badan Penerbit - Undip. Semarang.

Hadi, S. (2002). Metodologi Riset. Andi Ofset. Yogyakarta.

Hamzan, W. dan Bayu, R. 2013. Hubungan Variabel Demografi dengan Respon Konsumen Terhadap Iklan Merk Top Coffe di Kota Denpasar. Jurnal Ekonomi, 2(9) : 1036-1052.

Howard, J.A. 1989. Consumer Behavior in marketing strategy. Prentice Hall, Inc. Englewood Clifs.

Jaolis F. 2011. Profil Green Consumers Indonesia: Identifkasi Segmen Dan Faktor-Faktor Yang Mempengaruhi Perilaku Pembelian Green Products. Jurnal Mitra Ekonomi dan Manajemen Bisnis 2(1): 18-39.

Junaedi, MFS. 2008. Pengaruh gender sebagai pemoderasi pengembangan model perilaku konsumen hijau di Indonesia. Kinerja. 12(1): 17-37.

Kasali, R. 2007. Membidik Pasar Indonesia Segmentasi Targeting Positioning. PT Gramedia Pustaka Utama. Jakarta.

Kotler, P. dan Armstrong, G. 2012. Principles of Marketing. Edisi keempat belas. Pearson-Prentice Hall.: New Jersey.

Lee, K.H. 2009. Why and how to adopt green management into business organizations?: The case study of Korean SMEs in manufacturing industry. Management Decision. 47(7) : 1101-1121. 
Mostafa, M. M. (2006). Antecedents of Egyptian Consumers' Green Purchase Intentions: A Hierarchical Multivariate Regression Model. Journal of International Consumer Marketing. 19 : $97-126$.

Mowen, J.C. Minor, M. 2002. Perilaku Konsumen. Edisi kedua. Erlangga. Jakarta

Muzayanah, F.N. Suroso. A. I. dan Najib, M 2015. Faktor-Faktor Yang Memengaruhi Resistensi Pembelian Pangan Organik Dan Proses Pendidikan Konsumen. Jurnal Manajemen \& Agribisnis. $12(3): 163-173$.

Schiffman, L.G. dan Kanuk, L.L. 2008. Perilaku Konsumen.. Edisi Ketujuh. PT. Indeks. Jakarta.

Tsakiridou, E., Mattas, K. Dan Bazoche, P., 2012. Consumers response on the labels of fresh fruits and related implications on pesticide use. Food Economics, 9(1-2) : 129-134.

Widyastuti, N.P.A. dan Widagda. K. I. 2012. Pengaruh Faktor Demografi Dan Lingkungan Sosial Terhadap Keputusan Pembelian Dimediasi Oleh Perilaku Membaca Atribut Label. Jurnal Ekonomi. 2(1): 1398-1411.

Yahya. 2011. Pengaruh Variabel Demografi Konsumen Terhadap Keputusan Pembelian Produk. Jurnal Ekonomi. 8(1) : 23-40.

Yasa, B.M.A.S dan Ekawati, N.W. 2015. Peran Gender Dalam Menjelaskan Pengaruh Sikap Dan
Norma Subyektif Terhadap Niat Beli (Studi Kasus Produk Kosmetik Hijau Merek Oriflame Di Kota Denpasar). E-Jurnal Manajemen Unud, 4 (7): 17851797. 